\title{
The Survivor Unmet Needs Survey (SUNS) for haematological cancer survivors: a cross-sectional study assessing the relevance and psychometric properties
}

Alix Hall ${ }^{* *}$, Catherine D’Este ${ }^{2}$, Flora Tzelepis ${ }^{1}$, Rob Sanson-Fisher ${ }^{1}$ and Marita Lynagh ${ }^{1}$

\begin{abstract}
Background: Relevant and psychometrically sound needs assessment tools are necessary for accurate assessment of haematological cancer survivors unmet needs. No previous study has developed nor psychometrically evaluated a comprehensive needs assessment tool for use with population-based samples of haematological cancer survivors. This study aimed to assess the validity and reliability of the Survivor Unmet Needs Survey (SUNS) with haematological cancer survivors.
\end{abstract}

Methods: The relevance, content and face validity of the SUNS to haematological cancer survivors was assessed using qualitative interviews. Psychometric evaluation was conducted using data collected from haematological cancer survivors, aged 18-80 years at recruitment and recruited from four Australian cancer registries. Construct, convergent and discriminant validity; internal reliability and floor and ceiling effects were assessed. A second survey was completed by a sub-sample of survivors recruited from two of the four registries to assess test-retest reliability.

Results: Results from 17 qualitative interviews confirmed the relevance, face and content validity of the original items of the SUNS for use with haematological cancer survivors. Overall, 1,957 eligible haematological cancer survivors were contacted by the cancer registries. Of these 1,280 were sent a survey, and 715 returned a survey ( $37 \%$ of eligible survivors contacted and $56 \%$ of survivors sent a survey). A total of 529 survivors completed all 89 items of the SUNS and were included in the exploratory factor analysis. Exploratory factor analysis supported the original five-factor structure of the SUNS. Evidence for convergent validity was established, with all five domains of the SUNS illustrating a moderate positive correlation with all three subscales of the Depression Anxiety and Stress Scale (DASS-21). All Cronbach's alpha values were above 0.9 and all corrected item-total correlations were acceptable (>0.2). Criteria for discriminant validity was not met, with only 10 of the 15 (67\%) a-priori hypotheses supported. Test-retest reliability was acceptable for 40 of the 89 items (45\%) and for three of the five domains. Significant floor effects were evident for all five domains.

Conclusions: The SUNS demonstrates evidence for multiple features of validity and reliability as a measure of unmet needs for haematological cancer survivors. However, evidence supporting some psychometric properties was limited.

Keywords: Haematological cancer survivors, Psychometric evaluation, Needs assessment, Psycho-oncology, Unmet needs

\footnotetext{
* Correspondence: alix.hall@newcastle.edu.au

'Priority Research Centre for Health Behaviour, Faculty of Health, The University of Newcastle \& Hunter Medical Research Institute, Callaghan, NSW, Australia

Full list of author information is available at the end of the article
} 


\section{Background}

Haematological cancers are cancers of the blood or immune system [1-3]. Research has estimated haematological cancers to be the fourth most commonly diagnosed cancer type in the economically developed world [4]. Survival rates for some haematological cancers are increasing across several countries [5-7].

Haematological cancers are a unique and diverse subgroup of cancers. They can range from chronic and incurable, to acute and aggressive [3]. Treatment is equally variable and may include "watchful-waiting", chemotherapy, radiotherapy, immunotherapy and bone marrow transplant $[3,8]$. Like other cancers, haematological cancers impact on multiple aspects of a person's life, for some resulting in tiredness and fatigue $[9,10]$, anxiety and depression $[9,11]$ and social impacts including limited leisure time [12], missing family and social events [13], and employment-related outcomes [13-15].

Supportive care that is responsive to cancer survivors' physical, emotional, psychological, informational and social needs is necessary to achieve optimal cancer care $[16,17]$. Needs-based assessment provides a means of identifying patient concerns and the level of assistance patients perceive they need to address their concerns [18-20]. Data from needs-based assessments can be used in clinical practice to enhance patient-provider communication by efficiently identifying patient problems and directing appropriate care and services to patients [21]. Populationbased assessment of needs can be used to allocate resources, improve care and direct services towards the patient-identified areas where further assistance is most needed $[17,21,22]$.

Accurate and systematic identification of cancer survivors' needs is necessary to ensure appropriate supportive care is provided [22,23]. Consequently, needs-based assessment tools that are comprehensive, relevant and have strong psychometric properties are essential. Previous research has used various criteria to evaluate self-report scales [24-26], including key psychometric properties such as content validity, internal consistency, criterion validity, construct validity, reproducibility, responsiveness, floor and ceiling effects and interpretability [24].

Two comprehensive, cancer-survivor specific needs assessment tools have been developed and psychometrically evaluated: (1) the Cancer Survivors' Unmet Needs measure (CaSUN) [27], and (2) the Survivor Unmet Needs Survey (SUNS) [28]. The CaSUN was psychometrically assessed with 353 disease-free cancer survivors, diagnosed in the previous 1 to 15 years and recruited from two Australian hospitals [27]. The majority (97\%) of survivors who completed the CaSUN had been diagnosed with breast, gynaecologic, colorectal or prostate cancer [27]. The CaSUN was found to have good acceptability, internal consistency and face, content and construct validity; however item test-retest was low [27]. The SUNS was psychometrically evaluated with a heterogeneous sample of 550 cancer survivors, including haematological cancer survivors, diagnosed $1-5$ years previously and recruited from one Canadian cancer registry [28]. The SUNS was found to have high acceptability, item test-retest reliability, internal consistency and face, content and construct validity [28]. Neither of these tools has been psychometrically assessed for use in population-based samples of haematological cancer survivors. Given the variable nature and diverse treatment regimens of haematological cancers, the relevance and appropriateness of such tools for use with this population needs to be evaluated.

The SUNS was considered the most relevant of the two cancer survivor specific needs assessment instruments for psychometric evaluation with a populationbased sample of haematological cancer survivors. Unlike the CaSUN, the SUNS illustrates acceptable item testretest reliability and was psychometrically evaluated with a population-based sample of cancer survivors that included a larger proportion of haematological cancer survivors [28]. Despite the strong psychometric properties of the SUNS several important properties have not been assessed, including, convergent validity, discriminant validity (known-groups validity), test-retest reliability at the domain level, floor and ceiling effects, responsiveness and criterion validity.

This study aimed to evaluate the psychometric properties of the SUNS for use with adult haematological cancer survivors. This evaluation consisted of two phases: (1) qualitative evaluation of the relevance, content and face validity; and (2) quantitative survey of haematological cancer survivors for psychometric evaluation. This study also extended on the original psychometric evaluation of the SUNS by assessing convergent and discriminant validity, floor and ceiling effects and test-retest reliability at the domain level.

\section{Methods}

\section{The measure}

The Survivors Unmet Needs Survey (SUNS) measures cancer survivors' unmet needs over the last month, using 89 items across five domains: Financial Concerns (11 items), Emotional Health (33 items), Access and Continuity of Care (22 items), Information (8 items) and Relationships (15 items) [28]. Each item is scored from zero (no unmet need) to four (very high unmet need) [28].

\section{Phase 1: Relevance, face and content validity}

The relevance, face and content validity of the SUNS was assessed by two qualitative evaluations.

\section{Cultural relevance}

The wording of the SUNS was reviewed by a convenience sample of Australian researchers and members 
from the general population, who were known to the research team. Four items were reworded as a result of this process. The amended version of the SUNS was then reviewed by two native Canadians, who were also known to the research team. The two Canadian's considered the changes appropriate. A summary of this process is reported elsewhere [29].

\section{Relevance to target population}

A convenience sample of 17 haematological cancer survivors (consent rate $41 \%$ ) completed a semi-structured interview (average length 26 minutes) assessing their most prevalent unmet needs. Most survivors were male (59\%; $\mathrm{n}=10)$, diagnosed with non-Hodgkin's lymphoma $(59 \% ; \mathrm{n}=10)$ and almost half were aged between 50 and 59 years at time of diagnosis $(47 \% ; n=8)$. The interviews did not identify any additional concerns that were outside the scope of the original items; therefore no new items were included. All participants taking part in this interview study provided written informed consent. $\mathrm{Hu}$ man Research Ethics approval for this interview study was obtained from the University of Newcastle Human Research Ethics Committee and the relevant ethics committee associated with the specific cancer registry.

\section{Phase 2: Psychometric evaluation of the SUNS Sample}

A cross-sectional sample of haematological cancer survivors, aged between 18 and 80 years at time of recruitment were selected from four Australian state population-based cancer registries.

\section{Procedure}

The standard recruitment procedures of each registry were used. The first registry conducted a one-off crosssectional survey. On behalf of the researchers, survivors were mailed a questionnaire package from this cancer registry [30].

The remaining three registries employed a rolling recruitment method, where survivors were identified and approached on an ongoing basis between September 2011 and July 2012. A passive clinician consent model (clinician notification) [31,32] was used by these three registries. Eligible survivors were contacted by the registries via mail unless their clinician had previously notified the registry not to contact their patient. Survivors who consented to the registry passing on their contact details to the researchers were mailed a questionnaire package from the researchers. Non-responders were mailed a second questionnaire package approximately 4 weeks later, and contacted via telephone after a further 4 weeks.

Return of a completed survey was taken as voluntary consent to participate. Ethics approval was obtained from the University of Newcastle Human Research Ethics
Committee and the relevant ethics committees associated with each registry.

\section{Measures}

In addition to the SUNS, the following survivor information was used.

Patient, disease and treatment characteristics For consenting survivors data relating to their age, sex, postcode or location at diagnosis, cancer type and date of diagnosis were obtained from the cancer registries. Cancer recurrence and current treatments received were collected via self-report. De-identified data for non-participants were collected from all four cancer registries and deidentified data for all participants were collected from two cancer registries and included: age-group at diagnosis, sex, postcode or location at diagnosis and cancer type. Identified data for consenting survivors from the other two registries were used for participant and non-participant comparisons. Chi-squared analyses were used to compare characteristics of participants and non-participants.

Depression, anxiety and stress The Depression Anxiety and Stress Scale (DASS-21) is a self-report measure of depression, anxiety and stress over the past week, with three subscales each consisting of seven items [33]. Respondents rate each item on a scale from 0 ("not at all") to 3 ("very much") [34]. A total subscale score is calculated by summing all items in a subscale and multiplying by two [33] A higher score represents a higher level of the emotional state. Calculation of subscale scores requires completion of at least six of the seven subscale items [35]. The DASS21 has illustrated validity and reliability in both clinical and non-clinical populations $[33,34,36,37]$.

\section{Statistical analysis \\ Construct validity}

The distribution, frequencies and number of missing values for each of the 89 items of the SUNS were assessed. Items with more than $10 \%$ missing data or with more than $90 \%$ of responses occurring on only one of the response options were considered for potential exclusion.

Exploratory Factor Analysis (EFA) was used to assess the construct validity of the SUNS for use in a haematological cancer survivor population [38]. The principal factors method of EFA was employed due to the skewed distribution of the SUNS data $[39,40]$. The number of factors to retain was determined using the following three methods: (1) Kaiser-Guttman Criterion (Eigen value greater than one), (2) the break-point in the scree plot and (3) parallel analysis $[39,40]$. Multiple factor analyses were produced based on the results suggested by these three methods [40]. Results from all factor analyses were compared. The final factor structure was determined as having (i) at least 
3 items per factor, (ii) factor loadings above 0.3 [39] and considered conceptually relevant [41]. The number of cross-loadings was also examined. Original psychometric evaluation of the SUNS found high correlations between several factors [28]. To allow for correlations between the factors, a promax oblique rotation was used to simplify the factor structure [39-41]. Listwise deletion removed observations with any missing data on the SUNS.

\section{Convergent validity}

An association between unmet needs and anxiety, depression and/or stress has previously been found in heterogeneous samples of cancer survivors [18,42-44] and, to a lesser extent, haematological cancer survivors [9]. Spearman's rank correlations between the final factor scores of the SUNS and anxiety, depression and stress scores on the DASS-21 were calculated. Based on previous criteria used to assess the psychometric properties of self-report scales, a correlation coefficient above 0.4 was considered acceptable evidence of convergent validity [25].

\section{Known-groups (discriminant) validity}

Compared to their counterparts, a higher level of some unmet needs has been found for cancer survivors: reporting not being in remission (stable, recurrent and metastatic disease) [18,45]; diagnosed at a younger age [29,42,45-50]; and receiving some cancer treatments [43,45,46,51]. Based on this previous research it was hypothesized that median domain scores would be higher for: (1) survivors reporting a disease recurrence vs. survivors not reporting a disease recurrence; (2) survivors aged younger than 60 years at diagnosis vs. survivors aged 60 years or older at diagnosis; and (3) survivors currently receiving active treatment (including, chemotherapy, radiotherapy, bone marrow/stem cell transplant or harvest, hormone, antibody and targeted therapy) vs. those not receiving active treatment.

Domain scores were calculated by summing all items in a domain and dividing by the number of non-missing items for participants who answered more than $70 \%$ of items in a domain [29]. Due to the non-normal distribution of the data participant domain scores were compared by recurrence, age group at diagnosis and treatment status using the Wilcoxon rank sum test. Known-groups validity was considered acceptable if $\geq 75 \%$ of the proposed hypotheses were supported [24].

\section{Internal reliability}

Corrected item -total correlations above $0.2[25,52]$ and Cronbach's alpha between 0.7 and 0.95 [24] were considered acceptable indicators of internal reliability. Casewise deletion removed observations with missing data.

\section{Test-retest reliability}

Survivors who were recruited from two of the cancer registries, returned a completed initial survey after 4 April 2012, and consented to future contact from the researchers, were sent a second copy of the SUNS, 7-14 days after the receipt of their original survey. This time period was chosen to reduce recall bias and the likelihood of a change occurring in the participant's level of reported unmet needs [24]. Item test-retest reliability was assessed for each item using weighted Kappa, applying quadratic weighting [53]. A kappa coefficient $>0.6$ was considered acceptable [54]. Test-retest reliability at the domain level was assessed using intra-class correlation coefficients (ICCs) between mean domain scores from Time 1 and Time 2 . ICCs $\geq 0.7$ were considered acceptable [24].

\section{Floor and ceiling effects}

The percentage of respondents reporting the lowest and highest possible scores for each domain were calculated. Domains where $>15 \%$ of respondents obtained the lowest or highest possible scores were considered indicative of floor and ceiling effects [24].

\section{Sample size}

Based on previous recommendations, a sample size of 400 survivors was considered adequate for factor analysis and estimation of reliability and validity coefficients [55-57], while a sample size of at least 50 participants has been suggested for assessing adequate levels of testretest reliability [24].

\section{Results}

\section{Response rates}

A total of 1,957 eligible survivors were contacted by the cancer registries and 1,280 were sent a survey. Seven hundred and fifteen survivors returned a completed survey (37\% of all eligible survivors contacted and $56 \%$ of eligible survivors sent a survey); of these, $529(74 \%)$ completed all 89 items of the SUNS. A total of 146 eligible survivors were mailed a second copy of the SUNS; of these, 125 returned a completed survey (86\%).

\section{Participant and non-participant characteristics}

The majority of participants were diagnosed with NonHodgkin's lymphoma $(59 \% ; n=397)$ and most were male $(n=393 ; 58 \%)$. Approximately one third were aged between 60 and 69 years at diagnosis $(n=236 ; 35 \%)$. The median time since diagnosis was 35 months (quartile $1=20$, quartile $3=51$ ). Participants and nonparticipants were statistically significantly different in regards to age-group at diagnosis and cancer type (Table 1). 
Table 1 Statistically significant differences between participant and non-participant characteristics

\begin{tabular}{|c|c|c|c|c|c|}
\hline \multirow[t]{2}{*}{ Characteristics } & \multicolumn{2}{|c|}{$\begin{array}{l}\text { Participants } \\
(\mathrm{n}=715)^{\mathrm{a}}\end{array}$} & \multicolumn{2}{|c|}{$\begin{array}{l}\text { Non-participants } \\
\quad(n=1242)^{\mathrm{a}}\end{array}$} & \multirow[t]{2}{*}{ Chi-squared $\mathrm{X}^{2}(\mathrm{df}), p$} \\
\hline & $\bar{N}$ & $\%$ & $\bar{N}$ & $\%$ & \\
\hline Cancer Type & & & & & $11.05(3), 0.011$ \\
\hline Non-Hodgkin's Lymphoma (NHL) & 397 & $59 \%$ & 667 & $56 \%$ & \\
\hline Leukemia & 129 & $19 \%$ & 194 & $16 \%$ & \\
\hline Myeloma & 108 & $16 \%$ & 203 & $17 \%$ & \\
\hline Other lymphoma & 42 & $6.2 \%$ & 123 & $10 \%$ & \\
\hline Age at diagnosis & & & & & $25.12(4),<0.001$ \\
\hline $15-39$ & 54 & $8.0 \%$ & 169 & $14 \%$ & \\
\hline $40-49$ & 71 & $11 \%$ & 144 & $12 \%$ & \\
\hline $50-59$ & 179 & $26 \%$ & 263 & $22 \%$ & \\
\hline $60-69$ & 236 & $35 \%$ & 341 & $29 \%$ & \\
\hline $70+$ & 136 & $20 \%$ & 270 & $23 \%$ & \\
\hline
\end{tabular}

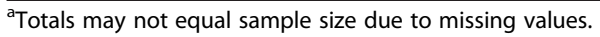

\section{Psychometric properties of the SUNS Construct validity}

The distributions of all items were skewed to the right. The median for all 89 items ranged from $0(\mathrm{SD}=0.72)$ to $1(\mathrm{SD}=1.28)$. The full range of response options were used for every item. No items had response options which included $90 \%$ or more of the distribution. Missing data for the 89 items ranged from $2.0 \%$ to $5.3 \%$.

Five factor structures were assessed: a 7-factor model based on the Kaiser criteria; a 3, 4, 5 and 6 factor model based on the scree plot; and a 5-factor model based on the parallel analysis. After rotation, the 5-factor model was deemed most appropriate, as all factors contained more than 3 items, the highest factor loading of each item was $>0.3$ [39] and the structure was considered the most conceptually relevant. Cross-loadings were present for all five models.

The factor loadings of the final 5-factor model are shown in Table 2. The 5-factor model closely reflected the original factor structure of the SUNS [28]. All items from the original Information, Access and Continuity of Care and Emotional Health domains loaded highest on factor 5 , factor 2 and factor 1, respectively. All but two of the 11 items from the original Financial Concerns domain loaded highest on factor 4. Two items originally from the Financial Concerns domain loaded more highly with all items from the Access and Continuity of Care domain. Twelve of the 15 items from the original Relationships domain loaded together on factor 3. Three items originally from the Relationships domain loaded highest on factor 1, with all items from the original Emotional Health domain. Conceptually these five items were most consistent with the original domains of the SUNS. Additionally, the factor loadings of these five items on their original domains was higher than the predetermined criterion of 0.3. Most cross-loadings in the 5-factor model occurred between items from the original Relationships domain cross-loading with items from the original Emotional Health domain. Based on statistical results and conceptual relevance, the original factor structure of the SUNS was identified as appropriate for use with haematological cancer survivors.

\section{Known-groups (discriminant) validity}

As shown in Table 3, haematological cancer survivors reporting a disease recurrence compared to those not reporting a recurrence, had higher median domain scores for the Financial Concerns, Access and Continuity of Care and Emotional Health domains. Median scores for all five domains were higher for younger $(<60$ years at diagnosis) than older ( $\geq 60$ years at diagnosis) survivors. Median domain scores for the Financial Concerns and Emotional Health domains were higher for survivors currently receiving treatment relative to those not receiving treatment.

\section{Convergent validity}

All five domains of the SUNS obtained a correlation coefficient above 0.4 with all three subscales of the DASS21. Correlation coefficients ranged from 0.44 to 0.73 .

\section{Internal consistency}

All corrected item-total correlations were above 0.2 , ranging from 0.61 to 0.88 . All five domains had high Cronbach's alpha values $(>0.9)$ (Table 4$)$.

\section{Test-retest reliability}

Weighted Kappa coefficients between item responses from Time 1 and Time 2 (mean of 28 days, SD $=16.1$ days) ranged from 0.25 to $0.76(\mathrm{M}=0.58 ; \mathrm{SD}=0.09)$. Forty items 
Table 2 Factor loadings for the $\mathbf{8 9}$ items of the Survivor Unmet Needs Survey (SUNS)

\begin{tabular}{|c|c|}
\hline $\begin{array}{l}\text { Domains from original } \\
\text { measure }\end{array}$ & Item \\
\hline \multirow[t]{8}{*}{ Information } & $\begin{array}{l}\text { Finding information about what signs to look for and when to be } \\
\text { concerned }\end{array}$ \\
\hline & Knowing which sources of information to trust \\
\hline & $\begin{array}{l}\text { Finding information about all my treatment choices, including no treatment } \\
\text { at all }\end{array}$ \\
\hline & Finding information about complementary or alternative therapies \\
\hline & Dealing with fears about cancer spreading \\
\hline & Dealing with worry about whether the treatment has worked \\
\hline & Dealing with feelings of worry (anxiety) between follow-ups \\
\hline & Dealing with not feeling sure that the cancer has gone \\
\hline
\end{tabular}

Financial concerns

Worry about earning money

Having to take a pension or disability allowance

Paying household bills or other payments

Adapting to living on a pension or disability allowance

Paying non-medical costs related to my cancer (travel, accommodation, special foods, etc.)

Finding what type of financial assistance is available and how to obtain it Finding car parking that I can afford at the hospital or clinic

Understanding what is covered by my medical insurance or benefits

Knowing how much time I would need away from work

Doing work around the house (cooking, cleaning, home repairs etc.)

Doing yard work (lawn mowing, etc.)

Access and continuity of care

Finding information about who I should contact if I have a problem or concern

$\begin{array}{ccccc}\begin{array}{c}\text { Factor } \\ \mathbf{1}\end{array} & \begin{array}{c}\text { Factor } \\ \mathbf{2}\end{array} & \begin{array}{c}\text { Factor } \\ \mathbf{3}\end{array} & \begin{array}{c}\text { Factor } \\ \mathbf{4}\end{array} & \begin{array}{c}\text { Factor } \\ \mathbf{5}\end{array} \\ & 0.34 & & & \mathbf{0 . 5 1} \\ & & & & \\ & & & & \mathbf{0 . 5 9} \\ & 0.38 & & & \mathbf{0 . 6 1} \\ & & & \\ 0.32 & & & \mathbf{0 . 5 1} \\ 0.33 & & & \mathbf{0 . 6 2} \\ 0.43 & & & \mathbf{0 . 5 9} \\ 0.34 & & & \mathbf{0 . 5 5} \\ & & & \mathbf{0 . 4 9}\end{array}$

0.75

0.76

0.84

0.82

0.62

0.46

$0.43^{*}$

0.34

$0.43^{*}$

0.56

0.39

0.33

0.39

Finding information about cancer and its effects in a way I can understand Finding out what is involved in follow-up care

Making sure my family doctor could get information from specialists

0.65

Making sure I was treated in a hospital or clinic that was as physically pleasant as possible

0.67

Having access to cancer services close to my home

0.50

Having access to cancer services at night and on weekends

0.71

Getting appointments with my family doctor quickly enough

0.63

Getting appointments with specialists quickly enough (oncologist,

0.79 surgeon etc.)

Getting follow-up tests quickly enough

Getting test results quickly enough

0.79

Having access to care from other health specialists (e.g. dieticians, physiotherapists, occupational therapists)

Making sure I had choices about which hospital or clinic I could go to

Making sure health care workers had access to my medical information when planning services for me

0.85

Feeling comfortable in the waiting room

Making sure I had enough time to ask my doctor or nurse questions

0.81

Making sure all my health care workers had all the medical files related to

0.87 my cancer care 
Table 2 Factor loadings for the $\mathbf{8 9}$ items of the Survivor Unmet Needs Survey (SUNS) (Continued)

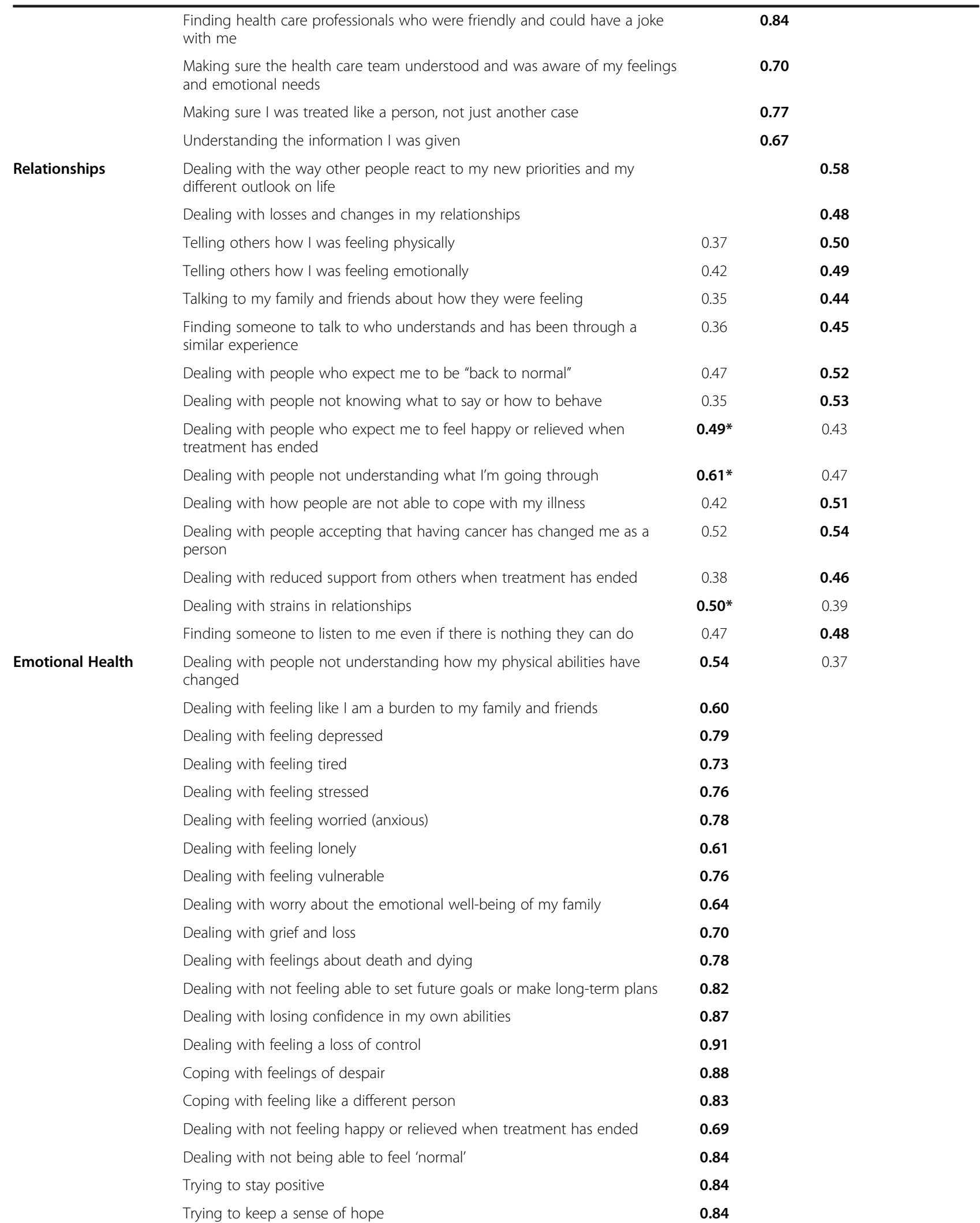


Table 2 Factor loadings for the 89 items of the Survivor Unmet Needs Survey (SUNS) (Continued)

\begin{tabular}{ll}
\hline Dealing with feeling guilty about what I have put others through & $\mathbf{0 . 7 8}$ \\
Dealing with being told I had cancer & $\mathbf{0 . 6 3}$ \\
Wanting to reflect on what I have achieved & $\mathbf{0 . 6 6}$ \\
Dealing with not wanting to do the things I used to do & $\mathbf{0 . 8 3}$ \\
Knowing how to relax & $\mathbf{0 . 7 9}$ \\
Dealing with feelings of isolation & $\mathbf{0 . 7 0}$ \\
Coping with having a bad memory or lack of focus & $\mathbf{0 . 7 9}$ \\
Dealing with changes in how my body appears & $\mathbf{0 . 6 7}$ \\
Dealing with changes in my physical ability & $\mathbf{0 . 7 8}$ \\
Coping with going back into the 'real' world & $\mathbf{0 . 7 3}$ \\
Coping with things not going back to how they were before I had cancer & $\mathbf{0 . 8 5}$ \\
Dealing with missing important events like holidays & $\mathbf{0 . 7 0}$ \\
Support for finding meaning or new purpose in life & $\mathbf{0 . 7 3}$
\end{tabular}

*Items loaded highest on a factor that was not their original domain. However, based on conceptual relevance and that all of these items loaded $>0.3$ on their original domain all of these items were kept within their original domain.

(45\%) met the criteria for acceptable item test-retest reliability. ICC's between mean domain scores at Time 1 and Time 2 ranged from 0.61 to 0.77 (Financial Concerns ICC $=0.61,95 \%$ CI: 0.48, 0.71; Access and Continuity of Care $\mathrm{ICC}=0.68,95 \% \mathrm{CI}: 0.57$, 0.77; Relationships $\mathrm{ICC}=$ 0.72, 95\% CI: 0.62, 0.79; Information ICC $=0.73$, 95\% CI: 0.63, 0.81; Emotional Health ICC $=0.77,95 \%$ CI: 0.68, 0.83).

\section{Floor and ceiling effects}

Floor effects were observed for all five domains. Few ceiling effects were observed (Table 4).

\section{Discussion}

The study results provide initial support for the SUNS as a suitable measure of unmet needs in adult haematological cancer survivors. Qualitative interviews with members of the target population verified the relevance of the items and supported the face and content validity of the measure.
Quantitative analyses demonstrated strong psychometric properties, across multiple aspects of validity and reliability. However, evidence for some areas of reliability and validity were limited and require further investigation.

The original 5-factor structure of the SUNS was deemed most statistically and conceptually appropriate for use with haematological cancer survivors. However, the results from the factor analysis showed several discrepancies relative to the structure of the original SUNS. In particular three items originally from the Relationships domain loaded highest with items from the original Emotional Health domain. The majority of cross-loadings were also found between items from the original Relationships domain with items from the Emotional Health domain. It is likely that emotional and relationship needs are highly related; these domains had a high correlation $\left(r_{s}=0.848\right)$ in the original psychometric evaluation of the SUNS [28]. Future research should further evaluate the appropriateness

Table 3 Median domain scores of haematological cancer survivors in relation to cancer recurrence, age at diagnosis and current treatment

\begin{tabular}{|c|c|c|c|c|c|c|c|c|c|c|c|c|c|c|c|}
\hline \multirow[b]{3}{*}{ Domain } & \multicolumn{5}{|c|}{ Cancer recurrence } & \multicolumn{5}{|c|}{ Age at diagnosis } & \multicolumn{5}{|c|}{$\begin{array}{l}\text { Current treatment of chemotherapy, } \\
\text { radiation, bone marrow/stem cell } \\
\text { harvest/transplant, hormone or antibody) }\end{array}$} \\
\hline & \multicolumn{2}{|r|}{ Yes } & \multicolumn{2}{|c|}{ No/unsure } & \multirow[b]{2}{*}{ p-value ${ }^{a}$} & \multicolumn{2}{|c|}{$<60$ years } & \multicolumn{2}{|c|}{$\geq 60$ years } & \multirow[b]{2}{*}{ p-value ${ }^{a}$} & \multicolumn{2}{|c|}{ Yes } & \multicolumn{2}{|r|}{ No } & \multirow[b]{2}{*}{ p-value ${ }^{a}$} \\
\hline & $\mathbf{n}$ & Median & $\mathrm{n}$ & Median & & $\mathrm{n}$ & Median & $\mathrm{n}$ & Median & & $\mathrm{n}$ & Median & $\mathrm{n}$ & Median & \\
\hline Information & 149 & 0.38 & 499 & 0.38 & 0.13 & 291 & 0.63 & 350 & 0.13 & $<0.001^{*}$ & 147 & 0.50 & 525 & 0.25 & 0.07 \\
\hline Financial concerns & 151 & 0.36 & 502 & 0.18 & $0.02^{*}$ & 293 & 0.36 & 353 & 0.09 & $<0.001^{*}$ & 149 & 0.36 & 526 & 0.18 & $0.005^{*}$ \\
\hline $\begin{array}{c}\text { Access and continuity } \\
\text { of care }\end{array}$ & 154 & 0.14 & 508 & 0.09 & $0.01^{*}$ & 295 & 0.14 & 356 & 0.05 & $<0.001^{*}$ & 152 & 0.18 & 532 & 0.09 & 0.05 \\
\hline Relationships & 154 & 0.33 & 509 & 0.27 & 0.25 & 293 & 0.53 & 358 & 0.07 & $<0.001^{*}$ & 151 & 0.40 & 533 & 0.27 & 0.28 \\
\hline Emotional Health & 155 & 0.68 & 509 & 0.33 & $0.02^{*}$ & 294 & 0.55 & 357 & 0.21 & $<0.001^{*}$ & 151 & 0.58 & 534 & 0.30 & $0.008^{*}$ \\
\hline
\end{tabular}

*Statistically significant at 5\% significance level, confirming original hypothesis for known-groups (discriminant) validity.

ap-value from Wilcoxon rank sum test. 
Table 4 Cronbach's alpha coefficient and percentage of participants reporting the lowest and highest possible score for each of the five domains of the Survivor Unmet Needs Survey (SUNS)

\begin{tabular}{lllllll}
\hline Domain & $\begin{array}{l}\text { Number of participants } \\
\text { answering all domain } \\
\text { items } \mathbf{a}^{\mathbf{a}}\end{array}$ & $\begin{array}{l}\text { Cronbach's } \\
\text { alpha }\end{array}$ & $\begin{array}{l}\text { Number of participants } \\
\text { answering } \mathbf{7 0 \%} \text { of } \\
\text { domain items }\end{array}$ & $\begin{array}{l}\mathbf{n}(\%) \\
\text { lowest } \\
\text { score }\end{array}$ & $\begin{array}{l}\mathbf{n}(\%) \\
\text { highest } \\
\text { score }\end{array}$ & $\begin{array}{l}\text { Median (First Quartile } \\
\text { and third Quartile) }\end{array}$ \\
\hline $\begin{array}{l}\text { Information } \\
\begin{array}{l}\text { Financial } \\
\text { concerns }\end{array}\end{array}$ & 652 & 0.93 & 686 & $267(39)$ & $0(0.0)$ & $0.38(0.0,1.14)$ \\
$\begin{array}{l}\text { Access and } \\
\text { continuity of care }\end{array}$ & 650 & 0.92 & 689 & $267(39)$ & $2(0.3)$ & $0.18(0.0,0.82)$ \\
Relationships & 680 & 0.97 & 698 & $285(41)$ & $1(0.1)$ & $0.09(0.0,0.55)$ \\
Emotional health & 625 & 0.97 & 698 & $252(36)$ & $3(0.4)$ & $0.27(0.0,1.07)$ \\
\hline
\end{tabular}

aparticipants answering all items in the domain and included in the calculation of Cronbach's alpha.

barticipants answering $>70 \%$ of items in a domain and included in the calculation of floor and ceiling effects.

of the 5-factor structure of the SUNS for use with haematological cancer survivors.

While most (10 out of $15 ; 67 \%)$ of our hypotheses relating to known-groups validity were supported, the scale did not meet the specified criteria for acceptable known-groups validity [24]. Three of our five hypotheses relating to the expected differences in domain scores between survivors receiving treatment, compared with those not receiving treatment, were not supported. It is possible that only specific treatment types affect cancer survivor unmet needs. For instance, previous studies have found an association between cancer survivor unmet needs and chemotherapy $[43,45,46]$ and radiotherapy $[45,46,51]$ treatment, while a study of multiple myeloma survivors found no difference in the supportive care needs of survivors who had received a bone marrow transplant compared to those who did not receive this treatment [9]. We were unable to compare the unmet needs of survivors by individual treatment types due to the small number of survivors currently receiving each individual treatment type.

Internal consistency was high with all corrected itemtotal correlations above 0.6 and all Cronbach's alpha values above 0.9. However, it is possible that the high Cronbach's alpha values reflect some redundancy within the scale's items [24]. This seems particularly likely for the domains of Access and Continuity of Care, Relationships and Emotional Health, which all demonstrated Cronbach's alpha values above the recommended criteria of 0.95 [24]. This finding is consistent with the results from the original psychometric evaluation of the SUNS [28]. The Cronbach's alpha values for these three domains may have also been inflated due to the large number of items $(\geq 15)$ within each of the domains [24]. Consequently, a shorter scale may be warranted. At 89 items, this seems reasonable, particularly if this scale is to be routinely applied in research and clinical practice. Development of the Short Form SUNS (SF-SUNS) with a large, heterogeneous sample of Canadian cancer survivors has recently been conducted [58]. It is recommended that future studies assess the validity and reliability of the SF-SUNS with haematological cancer survivors.

Unfortunately, the majority of items (55\%) illustrated low test-retest reliability. These items may lack stability and therefore may not be appropriate for detecting changes in these needs over time. However, the mean Kappa statistic for items in this study was higher than the mean Kappa statistic reported for item test-retest of the CaSUN (0.58 vs. 0.13) [27], which has previously been used to assess the unmet needs of haematological cancer survivors $[9,49]$. Additionally, test-retest reliability at the domain level was not acceptable for two domains. It is possible that the time frame between survivors returning the initial survey and test-retest survey (mean $=28$ days) was too long. As the SUNS assesses unmet needs over the past month, it is possible that survivors experienced a true change in the level of some of their unmet needs. Further research utilising a shorter time period between initial and follow-up surveys is needed to confirm the test-retest reliability of the SUNS for haematological cancer survivors.

Floor effects were present for all five domains, indicating that most survivors were experiencing low levels of unmet needs across all five domains. Consequently, the ability of the SUNS to detect improvements in haematological cancer survivors' unmet needs may be impaired, thus impacting on the responsiveness of the scale [24]. Floor effects are not uncommon for cancer specific needs assessment measures [18,52]. However, this may not be a limitation of the scale but may instead be an accurate reflection that many cancer survivors are in fact doing well and have few unmet needs. This is a possibility, with almost a quarter (21\%) of Australian and Canadian haematological cancer survivors reporting no unmet needs on all 89 items of the SUNS in a previous study conducted by the authors [29]. Alternatively, the floor effects may also be influenced by possible sampling 
bias, as survivors experiencing a high level of unmet needs may be less likely to participate in research.

We conducted a thorough and rigorous psychometric evaluation of the SUNS. However, there were some limitations. Due to the cross-sectional design, the predictive validity and responsiveness of the scale were unable to be assessed. Future research should conduct longitudinal studies with haematological cancer survivors to confirm these other psychometric properties of the SUNS. Criterion validity was also not assessed due to the lack of a gold standard needs assessment tool. Despite the inclusion of a qualitative component to our psychometric evaluation, survivors were not asked to review the relevance of each individual item of the SUNS. Instead, an open-ended interview was conducted to discuss survivors' most prevalent/important unmet needs. To further strengthen the content validity of the SUNS for this population, the relevance of each individual item should be confirmed via direct feedback from haematological cancer survivors.

Study limitations include the low response rate (37\% of all eligible survivors contacted and 56\% of all eligible survivors sent a survey). However this is consistent with previous registry-based studies that have reported low response rates of $49 \%$ of a large heterogeneous sample of Canadian cancer survivors [28], 43\% of a sample of nonHodgkin's lymphoma survivors [59], 41\% of a large heterogeneous sample of Australian cancer survivors [45], 34\% of a large heterogeneous sample of America cancer survivors [60] and $8 \%$ of adolescent and young adult cancer patients [31]. In an effort to overcome this limitation, multiple efforts were made to increase the response rates of haematological cancer survivors approached for this study. Strategies included assessing the effectiveness of a tailored invitation letter to improve response rates to survivors recruited from Registry A [30], and the inclusion of several evidence-based strategies for increasing questionnaire response rates for survivors recruited from Registries B, C and $\mathrm{D}$, such as the use of multiple reminders to nonresponders and reducing the length of the survey sent to survivors [61]. In addition, non-participant and participant age at diagnosis and cancer type were statistically significantly different. These limitations may affect the generalizability of these results to the entire population of haematological cancer survivors.

\section{Conclusions}

Needs-based assessment is a vital step in achieving optimal supportive care. However, no previous multi-dimensional needs assessment tool has been psychometrically evaluated for use with a population-based sample of haematological cancer survivors. The present study fills this gap by identifying the SUNS as a suitable measure of unmet needs in haematological cancer survivors. This study also extends on the original psychometric evaluation of the SUNS by assessing additional psychometric properties, including convergent and known-groups validity, and floor and ceiling effects. In the future, large-scale longitudinal studies should assess responsiveness, predictive validity and testretest reliability, and also confirm the factor structure of the SUNS with haematological cancer survivors.

\begin{abstract}
Abbreviations
SUNS: Survivor Unmet Needs Survey; DASS-21: Depression Anxiety and Stress Scale 21 items; CaSUN: Cancer Survivors' Unmet Needs measure;

EFA: Exploratory factor analysis; SD: Standard deviation; ICC: Intra-correlation coefficient; SF-SUNS: Short Form Survivor Unmet Needs Survey.
\end{abstract}

\section{Competing interests}

The authors declare that they have no competing interests.

\section{Authors' contributions}

$\mathrm{AH}$ and RSF developed the aims for this manuscript. AH, FT and ML assisted in organizing data collection. AH and FT developed, conducted and oversaw data cleaning procedures. AH and CD conducted statistical analysis. All authors contributed to the interpretation of the results. AH wrote and prepared the manuscript. All authors reviewed, edited and approved the manuscript.

\section{Authors' information}

$\mathrm{AH}$ is a PhD student investigating the unmet needs of haematological cancer survivors. She has previous experience in the area of cancer survivorship. CD is a professor in biostatistics. She has over 18 years of experience in health research and teaching. FT is a post-doctoral research fellow. She was awarded a 3-year Leukaemia Foundation of Australia/Cure Cancer Australia Foundation Fellowship (2011-2013), to investigate haematological cancer survivors' perceptions of quality of care. RSF is a Laureate Professor of Health Behaviour with over 20 years of experience and an order of Australia award. RSF has research expertise in a number of different areas in health behaviour, including: addressing the psychosocial needs of cancer patients and improving health outcomes for vulnerable populations. ML is a senior lecturer and researcher in the area of health behaviour. ML's research interests include: health behaviour change, tobacco control and assessment of unmet needs of haematological cancer survivors and their support persons.

\section{Acknowledgements}

This project was co-funded by beyondblue and Cancer Australia (Grant ID: 569290). Miss Hall was funded by an Australian Postgraduate Award and was previously funded by a 2012 Asia Australia Prime Minister's Endeavour Award. Dr Flora Tzelepis was supported by a Leukaemia Foundation of Australia and Cure Cancer Australia Foundation Post-Doctoral Research Fellowship.

The authors would also like to acknowledge the infrastructure support from Hunter Medical Research Institute and the University of Newcastle. They are grateful for all the hard work and assistance of the registry staff; Ms Sandra Dowley and Miss Clara Davis for data entry; Miss Ally Logatchova, Dr Emily Cameron, Miss Hannah Small and Miss Lara Ryan for assistance with data cleaning. They would also like to acknowledge the time and effort provided by the survivors who took part in this research; the authors greatly appreciate their involvement as without their assistance this research would not be possible.

\section{Author details}

'Priority Research Centre for Health Behaviour, Faculty of Health, The University of Newcastle \& Hunter Medical Research Institute, Callaghan, NSW, Australia. ${ }^{2}$ National Centre for Epidemiology and Population Health, Research School of Population Health, ANU College of Medicine, Biology \& Environment, Australian National University, Acton, Canberra, ACT, Australia.

Received: 20 October 2013 Accepted: 30 April 2014

Published: 9 May 2014 


\section{References}

1. Butters G: Blood cancers, chemotherapy and the risks of neutropenia. Nurs Times 2011, 107:19.

2. National Institute for Clincial Excellence (NICE): Health Care Services for Haematological Cancers. London: National Health Service; 2003.

3. National Institute for Clinical Excellence (NICE): Guidance On Cancer Services Improving Outcomes In Haematological Cancers: The Manual. London: National Health Service; 2003.

4. Smith A, Howell D, Patmore R, Jack A, Roman E: Incidence of haematological malignancy by sub-type: A report from the Haematological Malignancy Research Network. Br J Haematol 2011, 105:1684-1692.

5. American Cancer Society: Cancer Facts and Figures 2012. Atlanta, Georgia: American Cancer Society Inc; 2012.

6. Australian Institute of Health and Welfare (AlHW): Cancer survival and prevalence in Australia: period estimates from 1982 to 2010, Cancer Series no. 69. Cat. no. CAN 65. Canberra: AlHW; 2012.

7. Verdecchia A, Francisci S, Brenner H, Gatta G, Micheli A, Mangone L, Kunkler I, The EUROCARE-4 working group: Recent cancer survival in Europe: A 2000-02 period analysis of EUROCARE-4 data. Lancet Oncol 2007, 8:784-796.

8. Horn J, Campbell K: Support needs of patients with a diagnosis of follicular lymphoma. Cancer Nurs Pract 2010, 9:34-37.

9. Molassiotis A, Wilson B, Blair S, Howe T, Cavet J: Unmet supportive care needs, psychological well-being and quality of life in patients living with multiple myeloma and their partners. Psychooncology 2011, 20:88-97.

10. Manitta V, Zordan R, Cole-Sinclair M, Nandurkar H, Philip J: The symptom burden of patients with hematological malignancy: A cross-sectional observational study. J Pain Symptom Manage 2011, 42:432-442.

11. Montgomery C, Pocock M, Titley K, Lloyd K: Predicting psychological distress in patients with leukaemia and lymphoma. J Psychosom Res 2003, 54:289-292.

12. Molassiotis A, Wilson B, Blair S, Howe T, Cavet J: Living with multiple myeloma: Experiences of patients and their formal caregivers. Support Care Cancer 2011, 19:101-111.

13. Paul CL, Hall AE, Carey ML, Cameron EC, Clinton-McHarg T: Access to care and impacts of cancer on daily life: Do they differ for metropolitan versus regional hematological cancer survivors? I Rural Health 2013, 29:S43-S50.

14. Mehnert A: Employment and work-related issues in cancer survivors. Crit Rev Oncol Hematol 2011, 77:109-130.

15. Taskila T, Lindbohm L: Factors affecting cancer survivors' employment and work ability. Acta Oncol 2007, 46:446-451.

16. State Government Victoria: Providing Optimal Cancer Care: Supportive care policy for Victoria, Victorian Government Department of Human Services. Melbourne: Metropolitan Health and Aged Care Services Division; 2009.

17. Howell D, Currie S, Mayo S, Jones G, Boyle M, Hack T, Green E, Hoffman L, Simpson J, Collacutt V, McLeod D, Digout C: A Pan-Canadian clinical practice guideline: Assessment of psychosocial health care needs of the adult cancer patient. Toronto: Canadian Partnership Against Cancer (Cancer Journey Action Group) and the Canadian Association of Psychosocial Oncology; 2009.

18. Boyes AW, Girgis A, Lecathelinais C: Brief assessment of adult cancer patients' perceived needs: development and validation of the 34-item Supportive Care Needs Survey (SCNS-SF34). J Eval Clin Pract 2009, 15:602-606.

19. Sanson-Fisher R, Girgis A, Boyes A, Bonevski B, Burton L, Cook P, The Supportive Care Review Group: The unmet supportive care needs of patients with cancer. Cancer 2000, 88:225-236.

20. Harrison JD, Young JM, Price MA, Butow P, Solomon MJ: What are the unmet supportive care needs of people with cancer? A systematic review. Support Care Cancer 2009, 17:1117-1128

21. Wen KY, Gustafson DH: Needs assessment for cancer patients and their families. Health Qual Life Outcomes 2004, 2:11

22. Osse BHP, Vernooij-Dassen MJFJ, de Vree BPW, Schade E, Grol RPTM: Assessment of the need for palliative care as perceived by individual cancer patients and their families: A review of instruments for improving patient participation in palliative care. Cancer 2000, 88:900-911.

23. Howell D, Mayo S, Currie S, Jones G, Boyle M, Hack T, Green E, Hoffman L, Collacutt V, McLeod D, Simpson J: Psychosocial health care needs assessment of adult cancer patients: A consensus-based guideline. Support Care Cancer 2012, 20:3343-3354.
24. Terwee CB, Bot SDM, de Boer MR, van der Windt DAWM, Knol DL, Dekker J, Bouter LM, de Vet HCW: Quality criteria were proposed for measurement properties of health status questionnaires. J Clin Epidemiol 2007, 60:34-42.

25. Pearce NJM, Sanson-Fisher R, Campbell HS: Measuring quality of life in cancer survivors: A methodological review of existing scales. Psychooncology 2008, 17:629-640

26. Scientific Advisory Committee of the Medical Outcomes Trust: Assessing health status and quality-of-life instruments: Attributes and review criteria. Qual Life Res 2002, 11:193-205.

27. Hodgkinson K, Butow P, Hunt GE, Pendlebury S, Hobbs KM, Lo SK, Wain G: The development and evaluation of a measure to assess cancer survivors' unmet supportive care needs: The CaSUN (Cancer Survivors' Unmet Needs measure). Psychooncology 2007, 16:769-804.

28. Campbell HS, Sanson-Fisher R, Turner D, Hayward L, Wang XS, Taylor-Brown J: Psychometric properties of cancer survivors' unmet needs survey. Support Care Cancer 2010, 19:221-230.

29. Hall AE, Campbell HS, Sanson-Fisher R, Lynagh MC, D'Este C, Burkhalter R, Carey M: Unmet needs of Australian and Canadian haematological cancer survivors: A cross-sectional international comparative study. Psychooncology 2013, 22:2032-2038.

30. Hall AE, Sanson-Fisher RW, Lynagh MC, Threlfall T, D'Este CA: Format and readability of an enhanced invitation letter did not affect participation rates in a cancer registry-based study: A randomized controlled trial. J Clin Epidemiol 2013, 66:85-94.

31. Clinton-McHarg T, Carey M, Sanson-Fisher R, Tracey E: Recruitment of representative samples for low incidence cancer populations: Do registries deliver? BMC Med Res Methodol 2011, 11:5.

32. Beskow LM, Sandler RS, Weinberger M: Research recruitment through US central cancer registries: Balancing privacy and scientific issues. Am J Public Health 2006, 96:1920-1926.

33. Antony MM, Bieling PJ, Cox BJ, Enns MW, Swinson RP: Psychometric properties of the 42-item and 21-item versions of the Depression Anxiety Stress Scales in clinical groups and a community sample. Psychol Assess 1998, 10:176-181.

34. Clara IP, Cox BJ, Enns MW: Confirmatory factor analysis of the Depression-Anxiety-Stress Scales in depressed and anxious patients. J Psychopathology Behav Assessment 2001, 23:61-67.

35. School of Psychology University of New South Wales: DASS FAQ (Frequently Asked Questions). Accessed March 2013 [http://www2.psy.unsw.edu.au/ Groups/Dass/DASSFAQ.htm]

36. Ng F, Trauer T, Dodd S, Callaly T, Campbell S, Berk M: The validity of the 21 -item version of the Depression Anxiety Stress Scales as a routine clinical outcome measure. Acta Neuropsychiatr 2007, 19:304-310.

37. Henry JD, Crawford JR: The short-form version of the Depression Anxiety Stress Scales (DASS-21): Construct validity and normative data in large non-clinical sample. Brit J Clin Psychol 2005, 44:227-239.

38. de Vet HCW, Ader HJ, Terwee CB, Pouwer F: Are factor analytical techniques used appropriately in the validation of health status questionnaires? A systematic review on the quality of factor analysis of the SF-36. Qual Life Res 2005, 14:1203-1218.

39. Costello AB, Osborne JW: Best practices in exploratory factor analysis: Four recommendations for getting the most from your analysis. Prac Assess Res Eval 2005, 10:9.

40. Fabrigar LR, Wegener DT, MacCallum RC, Strahan EJ: Evaluating the use of Exploratory Factor Analysis in psychological research. Psychol Methods 1999, 4:272-299.

41. Worthington RL, Whittaker TA: Scale development research: A content analysis and recommendations for best practice. Couns Psychol 2006, 34:806-838.

42. Armes J, Crowe M, Colbourne L, Morgan H, Murrells T, Oakley C, Palmer N, Ream E, Young A, Richardson A: Patients' supportive care needs beyond the end of cancer treatment: A prospective, longitudinal survey. J Clin Oncol 2009, 27:6172-6179.

43. Beesley V, Eakin E, Steginga S, Aitken J, Dunn J, Battistutta D: Unmet needs of gynaecological cancer survivors: Implications for developing community support services. Psychooncology 2008, 17:392-400.

44. Harrison SE, Watson EK, Ward AM, Khan NF, Turner D, Adams E, Forman D, Roche MF, Rose PW: Primary health and supportive care needs of long-term cancer survivors: A questionnaire survey. J Clin Oncol 2011, 29:2091-2098.

45. Boyes AW, Girgis A, D'Este CA, Zucca A: Prevalence and correlates of cancer survivors' supportive care needs 6 months after diagnosis: A population-based cross-sectional study. BMC Cancer 2012, 12:150. 
46. Girgis A, Boyes A, Sanson-Fisher R, Burrows S: Perceived needs of women diagnosed with breast cancer: Rural versus urban location. Aust New Zeal Public Health 2000, 24:166-173.

47. Hall AE, Boyes AW, Bowman J, Walsh RA, James EL, Girgis A: Young adult cancer survivors' psychosocial well-being: A cross-sectional study assessing quality of life, unmet needs, and health behaviors. Support Care Cancer 2012, 20:1333-1341.

48. Li J, Girgis A: Supportive care needs: Are patients with lung cancer a neglected population? Psychooncology 2006, 15:509-516.

49. Lobb EA, Joske D, Butow P, Kristjanson LJ, Cannell P, Cull G, Augustson B: When the safety net of treatment has been removed: Patients' unmet needs at the completion of treatment for haematological malignancies. Patient Educ Couns 2009, 77:103-108.

50. Steginga SK, Occhipinti S, Dunn J, Gardiner RA, Heathcote P, Yaxley J: The supportive care needs of men with prostate cancer (2000). Psychooncology 2001, 10:66-75.

51. Aranada S, Schofield P, Weih L, Yates P, Milne D, Faulkner R, Voundouris N: Mapping the quality of life and unmet needs of urban women with metastatic breast cancer. Eur J Cancer Care 2005, 14:211-222.

52. Clinton-McHarg T, Carey M, Sanson-Fisher R, D'Este C, Shakeshaft A: Preliminary development and psychometric evaluation of an unmet needs measure for adolescents and young adults with cancer: The Cancer Needs Questionnaire - Young People (CNQ-YP). Health Qual Life Outcomes 2012, 10:13

53. Sim J, Wright CC: The Kappa statistic in reliability studies: Use, interpretation, and sample requirements. Phys Ther 2005, 85:257-268.

54. Landis JR, Koch GG: The measurement of observer agreement for categorical data. Biometrics 1977, 33:159-174.

55. Floyd FJ, Widaman KF: Factor analysis in the development and refinement of clinical assessment instruments. Psychol Assess 1995 7:286-299.

56. Charter RA: Sample size requirements for precise estimates of reliability, generalizability, and validity coefficients. J Clin Exp Neuropsychol 1999, 21:559-566.

57. Charter RA: Study samples are too small to produce sufficiently precise reliability coefficients. J Gen Psychol 2003, 130:117-129.

58. Campbell HS, Hall AE, Sanson-Fisher RW, Barker D, Turner D, Taylor-Brown J: Development and validation of the Short-Form Survivor Unmet Needs Survey (SF-SUNS). Support Care Cancer 2014, 22(4):107-109.

59. Hammond CTC, Beckjord EB, Arora NK, Bellizzi KM, Jeffery DD, Aziz NM: Non-Hodgkin's lymphoma survivors' fertility and sexual function-related information needs. Fertil Steril 2008, 90:1256-1258.

60. Smith T, Stein KD, Mehta CC, Kaw C, Kepner JL, Buskirk T, Stafford J, Baker F: The rationale, design, and implementation of the American Cancer Society's studies of cancer survivors. Cancer 2007, 109:1-12

61. Edwards PJ, Roberts I, Clarke MJ, Diguiseppi C, Wentz R, Kwan I: Methods to increase response to postal and electronic questionnaires (Review). Cochrane Database Syst Rev 2009, Issue 3. Art. No.: MR000008. doi:10.1002/14651858.MR000008.pub4.

doi:10.1186/1472-6963-14-211

Cite this article as: Hall et al:: The Survivor Unmet Needs Survey (SUNS)

for haematological cancer survivors: a cross-sectional study assessing the relevance and psychometric properties. BMC Health Services

Research 2014 14:211.

\section{Submit your next manuscript to BioMed Central and take full advantage of:}

- Convenient online submission

- Thorough peer review

- No space constraints or color figure charges

- Immediate publication on acceptance

- Inclusion in PubMed, CAS, Scopus and Google Scholar

- Research which is freely available for redistribution

Submit your manuscript at www.biomedcentral.com/submit
C BioMed Central 